\title{
EFFECT OF SINGLE DOSE LOW-LEVEL LASER THERAPY ON SOME SEQUALAE AFTER IMPACTED LOWER THIRD MOLAR SURGERY
}

\author{
Ahmed M. El Saeed *, Abdel-aged H. Al-Fakharany **
}

\begin{abstract}
Objective: This study was designed to evaluate the effect of single dose of low-level laser therapy on pain, swelling and trismus after impacted lower third molar surgery. Subjects and methods: Twenty patients with bilateral impacted lower third molars on both sides were selected. They were selected from those attending the out-Patient Clinics of Oral and Maxillofacial Surgery Department, Faculty of Dental Medicine, Boys, Cairo, Al Azhar University and Sayed Jalal University Hospital. The teeth of patients were removed in two separate operations. Postoperatively, the patients received laser therapy with energy of $4 \mathrm{~J} / \mathrm{cm} 2$ on one side and no laser energy was applied to the other side (placebo side). Swelling, trismus, and subjective assessment of pain on a visual analog scale were evaluated and compared between the laser-treated and placebo sides. . All readings were recorded and analyzed statistically. Results: There was statistically significant difference in pain, swelling and trismus between the laser treated and placebo sides $(\mathrm{p}>0.001)$. However, according to the clinical outcomes, swelling and trismus were less in the laser-treated side than in the placebo side. Conclusion: A single-session LLLT with a diode laser that was performed immediately after impacted tooth extraction gave a beneficial effect for pain reduction, anti-inflammatory processes and increase the maximum mouth opening.
\end{abstract}

KEY WORDS: Low-level laser therapy, pain, swelling and trismus, impacted lower third molar surgery.

\section{INTRODUCTION}

Lower third molar surgery is a common procedure performed by oral and maxillofacial surgeons. Surgical removal of impacted third molar often is followed by postoperative pain, swelling, and sometimes temporary loss of jaw function. Those factors may originate from the inflammatory process that is initiated by surgical trauma ${ }^{(1)}$. Different treatment modalities have been proposed to inhibit postoperative complications. This modality may be local or systemic administration of corticosteroid, nonsteroidal anti-inflammatory drugs, various flap designs, physical therapy and cryotherapy $^{(2,3)}$. Side effects such as gastrointestinal irritation, systemic bleeding tendency, and allergic reactions maybe arisen from these treatment ${ }^{(4)}$. Moreover, none of these treatments have proved to be satisfactory ${ }^{(5)}$. Low level laser therapy (LLLT) induce cellular bio stimulation, that can accelerate tissue regeneration, improve wound healing, and reduce pain and swelling. This action may be due to anti-inflammatory mechanisms by inhibition of interleukin-6, monocyte chemotactic protein-1, interleukin-10, and tumor necrosis factor-a. The clinical outcomes of LLLT depending on each laser parameter (such as repetitive sessions, application technique, application area, wavelength, irradiation time and amount of laser energy) ${ }^{(6,7)}$.

Until now, standardization of the LLLT applications has not been established yet ${ }^{(8)}$. It is remarkable that LLLT has been applied mostly at wavelengths $800 \mathrm{~nm}$ and require repetitive sessions ${ }^{(9)}$. These repetitive sessions in many of the recent studies needs more clinical visits and may compromise thyroid function ${ }^{(10,11)}$.A new generation of laser can be used in a single session and may solve this problem ${ }^{(12,13)}$.

\footnotetext{
* Dentist, Ministry of Health.

** Assistant Professor, Department of Oral and Maxillofacial Surgery, Faculty of Dental Medicine, Boys, Cairo AlAzhar University.
} 
A single dose diode laser at wave length of $980 \mathrm{~nm}$ was applied extra-orally at the insertion of the masseter muscle in edematous area to stimulate the surrounding tissues of the impacted lower third molar surgical area and may have a role in elimination of the postoperative problems, a factor that initiate the present study. The aim of the study was to evaluate the effect of single dose of LLLT on some sequalae after impacted lower third molar surgery.

\section{SUBJECTS AND METHODS}

This Randomized Controlled Clinical Trial study was conducted on twenty adult patients of both genders. All patients had bilateral mesioangular mandibular third molar indicated for extraction. Appropriate ethical clearance was granted from the institution in which the study was carried out, also an informed consent was obtained from all patients. The patients were selected from the Out Patient Clinic of the Oral \& Maxillofacial Surgery Department, Faculty of Dentistry, Al-Azhar University.

\section{Patients were divided into two groups:}

The study group: Patients were subjected to surgical removal of impacted teeth followed by single dose of LLLT. The control group: Patients were subjected to surgical removal of impacted teeth followed by placebo LLLT The inclusion criteria of this study were; Patients were selected with bilateral mesioangular impacted mandibular third molars, Age ranged from 19 to 46 years, Non-smoker and non-alcoholic While the exclusion criteria were; Presence of systemic diseases or uncontrolled medically compromised state that affect bone healing ,Patients with acute pericoronitis, Patients with corticosteroids therapy or taking bisphosphonate drugs for long time, Pregnancy and breast feeding, Presence of pathological changes around the impacted lower third molar.

\section{Laser device used: -}

A diode laser device (Doctor smile, Model Wiser. Made in Italy) was used in this study. This system operates with a continuous wave length of $980 \mathrm{~nm}$ and power density of $0.5 \mathrm{watt} / \mathrm{cm}^{2}$, bleaching handpiece was used.

\section{A-Preoperative phase}

All patients underwent pre-operative clinical examination: Patients' data were collected; name, gender and age, medical and dental histories were taken and the oral mucosa was examined by inspection and palpation. Also, all patients underwent standardized a pre-operative panoramic radiograph examination for overall view of the state of impacted tooth, its supporting periodontium and any pathological changes.

\section{B-Operative phase}

Surgical extraction was done under local anesthesia in two separate operations with a minimum 3-weeks interval. In a sequential manner, mucoperiosteal flap was elevated and bone was removed to remove lower third molars, in both groups in the same manner

In the study group, all the persons within the dental treatment room including the patient must wear adequate eye protection (eye glass), to avoid ocular hazards. In the study group LLLT (A diode laser device with continuous wavelength of $980 \mathrm{~nm}$ and power density of $0.5 \mathrm{watt} / \mathrm{cm}^{2}$ ) was applied for each patient in the study group, immediately following third molar surgery. Extraoral laser was performed by laser probe application, contacted with the skin. Energy was transmitted to a triangular region bordered by the masseter muscle insertion in the angle of the mandible, auricular tragus, and mesial margin of the mandibular second molar. After resetting the cumulative energy measurement to zero on the device, laser application was continued until the total energy reached the level of 50J 
$(50 \mathrm{~J} / 12 \mathrm{~cm} 2=4 \mathrm{~J} / \mathrm{cm} 2)$ on the device screen. The patients were blinded to the side that received laser energy (Figs 1). In the control group, LLLT application was simulated (LLLT device was off)

\section{C-Postoperative phase}

Medical and physical postoperative instruction were done as the following; Patients in both groups received the same types of postoperative prescription of antibiotics(Amoxicillin (Amoxil $\left.{ }^{\mathrm{TM}}\right) 1 \mathrm{~g}$. capsules twice daily and Metronidazole (Flagyl $\left.{ }^{\circledR}\right) 500 \mathrm{mg}$ tablets (t.d.s) for 7 days).Ibuprofen $\left(\right.$ Brufen $\left.^{\circledR}\right) 600$ mg tablets (t.d.s) for 3 days and then when necessary. Rinsing with Antiseptic mouthwash (Betadine ${ }^{\circledR}$ ) was prescribed, twice a day for 10 days except on the surgery day. All patients were asked to place gauze pack over the surgical area for 30 - 60 minutes. Ice packs were applied on the face, 30 minutes on, and 30 minutes off for the first day. Patients were asked to avoid smoking and hot drinks. All patients were asked to keep the mouth clean.

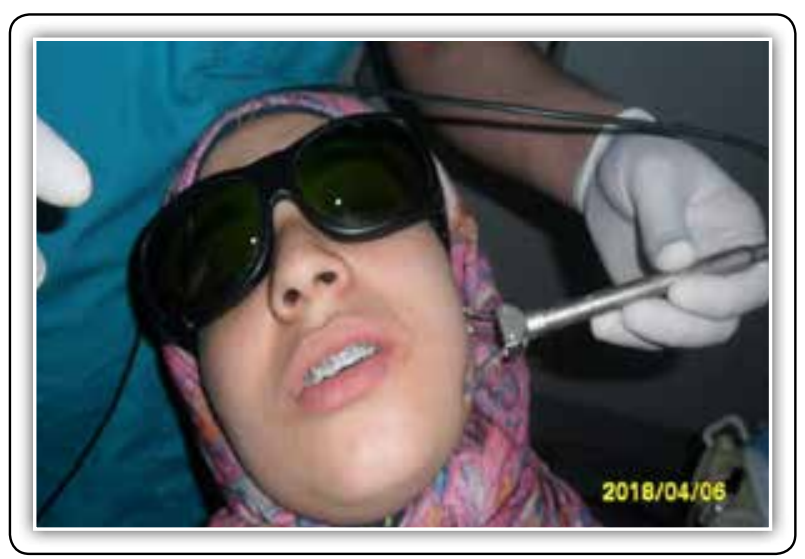

FIG (1) Photograph showing low level laser application in the study group.

\section{D- Follow up phase}

\section{Patients were evaluated clinically for:}

1. Evaluation of postoperative pain: Post-operative pain was assessed at $2^{\text {nd }}$ and $7^{\text {th }}$ days following surgery by asking the patient about level of the pain and recorded on a visual analog scale
(VAS). The VAS is a $10 \mathrm{~cm}$ linear scale, ranging from 0 (no pain) to 10 (worst possible pain).

2. MMO Assessment: At $2^{\text {nd }}$ and $7^{\text {th }}$ days postoperatively, the maximum mouth opening was measured he between the maxillary and mandibular central incisors with digital caliper and compared with preoperative measurements

3. Facial swelling evaluation: Postoperative swelling was assessed by the same way of preoperative facial measurement and comparing between them. These measurements were taken by flexible meters produced by IKEA. The preoperative measurements were the baseline values. The difference between each postoperative evaluation and baseline indicated the swelling for that day. The assessment of the postoperative swelling was carried out at the $2^{\text {nd }}$ and $7^{\text {th }}$ days after the procedure

Data were represented as mean and standard deviation. Repeated measures analysis of variance (ANOVA) test was used to compare numeric variables within the studied group of patients. Post Hoc test was done if ANOVA or Friedman tests were positive. Using SPSS version in all tests, result was considered statistically significant if the $\mathrm{p}$ - value was less than 0.05 .

\section{RESULTS}

This study included 40 impacted mandibular third molars in 20 patients (10 males and 10 females) aged from 19 to 46 years (mean age was $32.05 \pm 8.67$ years). All patients were with bilateral impacted third molars. In each of 20 patients, one tooth was included in the study group and the other was in the control group. There was no statistical significant different regarding age of both groups ( $p$ value $=0.835)$. None of the patients showed any adverse reactions to the applied treatment.

1. Pain: Pain level was high at $2^{\text {nd }}$ postoperative days in both groups, then decreased gradually by 
the time of evaluation, reached to the minimum level at the $7^{\text {th }}$ day. At the $2^{\text {nd }}$ postoperative day, the patients of the study group suffered from mild pain with the mean value of $4.68 \pm 1.00$ ). Also, the patients of the control group were suffered from moderate pain with the mean of $5.34 \pm 0.99$. At $7^{\text {th }}$ postoperative day, no pain was found in the study group (Mean:1.25 0.76 ) and mild pain was detected in the control group (Mean:2.63 \pm 0.86). In between groups, the pain value was decreased at whole period of evaluation in study group more than the control group with highly statistically significant differences, where ( $p$ value $<0.001)$.

2. Postoperative MMO: Maximum Mouth Opening (MMO) was assessed preoperatively using digital caliper to measure the distance between the incisal edges of the upper and lower central incisors. Preoperative mean value was $46.46 \pm 2.25$ ) in the study group and $46.46 \pm 2.25$ ) in the control group. At the 2nd postoperative day, the mean value of MMO was $27.27 \pm 2.34$ in the study group and $25.92 \pm 2.23$ in the control group, without statistical significant difference ( $p=0.07) \cdot$ MMO was decreased at the $2^{\text {nd }}$ postoperative day in comparing to preoperative value in control group more than the study group, where the mean value was and $20.54 \pm$ 0.47 and $19.19 \pm 0.40$ respectively and $p<0.001$. At the 7th postoperative day, the mean value of mouth opening in the study and control group were $40.18 \pm 2.67$ and $37.05 \pm 2.38$ respective$1 \mathrm{y}$, with $\mathrm{p}<0.001$. MMO was increased in both group at the $7^{\text {th }}$ days more than the $2^{\text {nd }}$ day. Significant increasing was observed in the study group more than control group, where, the change from $7^{\text {th }}$ day to preoperative was $9.42 \pm 0.55$ in the control group and $6.28 \pm 0.64$ in the study group $(\mathrm{p}<0.001)$

3. Facial Swelling: Preoperatively, the mean values of the facial swelling were $10.52 \pm 0.163$ and $10.52 \pm 0.164$ in the study and control group respectively. There was no significant difference between both groups regarding facial swelling $(\mathrm{P}=1.00)$. At the $2^{\text {nd }}$ postoperative day, the mean value was increased to $11.75 \pm 0.15$ in the study group and to $13.19 \pm 0.22$ in the control group, with significant increasing in the control group compared to the study group. The mean values were $12.61 \pm 0.21$ and $10.99 \pm 0.15$ in the control and study group respectively at the $7^{\text {th }}$ postoperative day with significant increasing of the facial swelling in the control group more than the study group $(p<0.001)$ (Figs 2, table 1).

TABLE (1) Showings mean value regarding postoperative pain in both groups, at $2^{\text {nd }}$ and $7^{\text {th }}$ days postoperatively. Data expressed as Mean \pm SD， P:Probability *:significance $<0.05$ Test used: Student's t-test

\begin{tabular}{|c|c|c|c|c|c|c|}
\hline \multirow{2}{*}{} & \multicolumn{2}{|c|}{$\begin{array}{c}\text { Group (1) } \\
(\mathrm{n}=20)\end{array}$} & \multicolumn{2}{|c|}{$\begin{array}{c}\text { Group(2) } \\
(\mathrm{n}=20)\end{array}$} & \multirow{2}{*}{ Test used } & \multirow{2}{*}{ P } \\
\cline { 2 - 6 } & Mean & \pm SD & Mean & \pm SD & & \\
\hline $2^{\text {nd }} \mathrm{DAY}$ & 4.68 & 1.00 & 5.34 & .99 & $\mathrm{t}=-2.093$ & $0.04^{*}$ \\
\hline $7^{\text {th }} \mathrm{DAY}$ & 1.25 & .76 & 2.63 & .86 & $\mathrm{t}=-5.339$ & $<0.001^{*}$ \\
\hline Change from $7^{\text {th }}$ day to $2^{\text {nd }}$ day & -3.43 & .32 & -2.72 & .22 & $\mathrm{t}=-8.174$ & $<0.001^{*}$ \\
\hline Percent of Change from $7^{\text {th }}$ day to $2^{\text {nd }}$ day & -75.50 & 11.51 & -52.06 & 7.72 & $\mathrm{t}=-7.564$ & $<0.001^{*}$ \\
\hline
\end{tabular}




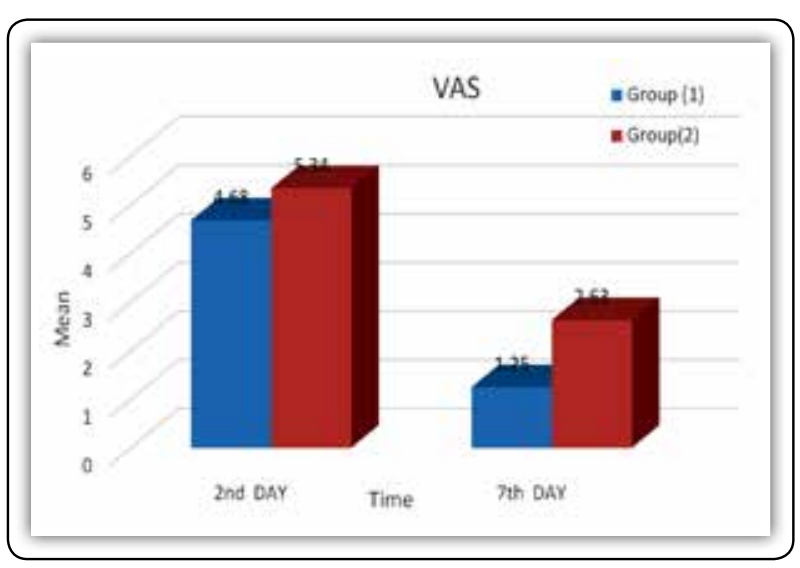

FIG (2) Bar chart showing comparison between two group regarding postoperative pain at $2^{\text {nd }}$, and $7^{\text {th }}$ days in both groups.

\section{DISCUSSION}

Local signs of inflammation, including pain, usually observed following the removal of impacted lower third molars. LLLT has been reported to prevent pain, swelling and trismus following the removal of impacted third molars, some of these studies reported a positive laser effect while others did not. Controversies over bio-stimulation of tissue induced by laser therapy still exist. In the present study, 20 patients (10 males and 10 females) aged from 19 to 46 years. According to age, there was no remarkable statistical difference between the young and old patients. In the present study, bilateral mesioangular impacted mandibular third molar were performed by one surgeon in the same patient. The patients included in this study had similar socioeconomic class, pain threshold and similar oral hygiene habits. Also, the operative trauma from the surgical procedures were similar in all patients of both groups with regard to the surgical difficulty and the duration of surgery. Ferrante et al in $2013^{(10)}$, concluded that, LLLT had been used to prevent postoperative pain, swelling and trismus after third molar surgery. However, the results were controversial, some studies reported a positive effect of laser energy, while the others showed no influence of LLLT. These controversial results may be due to variations in the study design, inconsistencies in measuring the variables related to postoperative sequelae after third molar surgery, as well as the use of different laser devices, hand piece types and irradiation parameters. Laser was used in our study applied extra orally at the insertion of the masseter muscle using a bleaching handpiece, thus obtaining a larger area of irradiation. Instead of, we used a higher wavelength with a higher power and we decreased the time of laser application in order to approach an energy density of $4 \mathrm{~J} / \mathrm{cm} 2$, (the recommended dosage to achieve an analgesic and anti-inflammatory effect).This system operates with a continuous type of radiation and continuous wave length $(980 \mathrm{~nm}$, $0.5 \mathrm{w}$ max power).Aras et al in 2010 ${ }^{14}$, compared extraoral and intraoral applications of laser therapy in combination after surgical removal of lower third molar and demonstrated that more effective of extraoral LLLT than intraoral LLLT for the reduction of postoperative trismus and swelling after thirdmolar surgery. The results of our study showed positive effects of LLLT for postoperative problems after the removal of lower third molars. Statistical analysis indicated a highly significant reduction in pain, swelling and trismus levels in the patients study group, compared to the control group. Other studies have similar results, but required more time of applications, repetitive session. Eshghpour et al in $2016^{(15)}$, evaluated the effect of LLLT in reducing swelling and pain after surgery of impacted lower wisdom teeth. The result showed that pain and swelling were significantly lower in experimental group compared to the control group. Saber et al in $2012^{(16)}$, applied intraoral LLLT, in a single session, immediately after impacted mandibular third molar surgery, and observed that no effect on pain. Postoperative pain in our study, was much less in study group if compared to control group, due to the analgesic effect of LLLT single dose and may be due to extraoral laser application to wide muscle area. The highest pain scores for each group were seen in the $2^{\text {nd }}$ day, thereafter, pain level tended to decline with the time until the $7^{\text {th }}$ postoperative day. A local inflammation of a surgical wound is not a phenomenon that takes place immediately after surgery, but 
it appears gradually and reaches its peak between 24 and 48 hours after the surgery ${ }^{(17)}$. Therefore, we evaluated two facial distances (vertical\& horizontal), at two different times at $2^{\text {nd }}$ and $7^{\text {th }}$ days after surgery. In the present study, overall swelling level during the total investigation period was significantly less in the study group compared to control group. This result reflects the superiority of the anti-inflammatory effect of LLLT and these findings were consistent with, Markovic and Todorovic in $2007^{(18)}$. Fernando et al ${ }^{(19)}$, founded that there was no difference between the laser-treated and placebo groups with regard to swelling on the $3^{\text {rd }}$ and $7^{\text {th }}$ postoperative days. This results may be due to low power output of the laser device used(30mw) and in the present study we used laser device with power output $(500 \mathrm{mw})$. Our findings with regard to trismus revealed that maximum mouth opening was significantly increase in the study group more than control group. This result similar to the study carried by Carrillo et al ${ }^{(20)}$, they noted that the amount of trismus seen in the laser group was significantly less than that seen in the placebo group up to 7 days post-surgery. This finding gives the impression that the analgesic and the anti-inflammatory effects of LLLT were superior to control group. Therefore less pain and swelling presented in the study group and as a consequence less trismus, this results in agreement with, Markovic and Todorovic in $2007^{(18)}$. The disagreements observed among the results of mentioned studies could be attributed to the use of different laser parameters, such as wavelength, power energy density, the frequency and duration of laser radiation, intraoral versus extraoral application, area of irradiation and received medical regime before and/or after surgery.

\section{CONCLUSIONS}

In conclusion, the LLLT performed with a $980 \mathrm{~nm}$ diode laser is a therapeutic option with clinically favorable effects on swelling and trismus, which are likely to develop following impacted tooth extraction. A single-session LLLT with a diode laser that was performed immediately after impacted tooth extraction give positive results for the healing and anti-inflammatory processes. The data suggested that the use of single-dose LLLT was more effective compared with routine management for the reduction of pain following third molar surgery.

\section{REFERENCES}

1. Mehrabi M, Allen J, Roser S. Therapeutic agents in perioperative third molar surgical procedures. Oral Maxillofac Surg Clin North Am 2007; 19:69-84.

2. Seymour R, Walton J. Pain control after third molar surgery. Int J Oral Surg 1984;13: 457-85.

3. Shapiro R, Cohen B. Perioperative pain control. Oral Maxillofacial North Am 1992; 4: 663 -74.

4. Little J, Falace D, Miller C, Rhodus N: Dental management of the medically compromised patient. 5th ed. Mosby, St. Louis; 1997; 299:458,86.

5. Kumar N, Prasad K, Ramanujam L. Evaluation of treatment outcome after Impacted mandibular third molar surgery with the use of autologous platelet-rich fibrin: a randomized controlled clinical study. J Oral Maxillofac Surg 2015; 73:1042 - 49.

6. Coluzzi D, Convissar R. Lasers in clinical dentistry. Dent Clin North Am 2004; 48:11-13.

7. Boschi E, Leite C, SaciuraV. Anti-inflammatory effects of low-level laser therapy $(660 \mathrm{~nm})$ in the early phase in carrageenan-induced pleurisy in rat. Lasers Surg Med 2008; 40:500-08.

8. Brignardello-Petersen R, Carrasco-Labra A, Araya I,Yanine N, Beyene J, Shah P. Is adjuvant laser therapy effective for preventing pain, swelling, and trismus after surgical removal of impacted mandibular third molars? Asystematic review and meta-analysis. J Oral Maxillofac Surg 2012; 70: 1789-801.

9. He L, Yu Y, Li J, Pan J, Zhuang R, Duan P. A systematic review and meta-analysis on the efficacy of low level laser therapy in the management of complication after mandibular third molar surgery. Lasers Med Sci 2015; 30:1779-88.

10. Ferrante M, Petrini M, Trentini P, Perfetti G, SpotoG. Effect of low-level laser therapy after extraction of impacted lower third molars. Lasers Med Sci 2013; 28: 845-49.

11. Hernandez L, Santistaban P, del Valle Soto M. Changes in mRNA of thyroglobulin, cytoskeleton of thyroid cells, and 
thyroid hormone levels induced by IR laser irradiation. Laser Therapy 1989; 1: 203-08.

12. López-Ramírez M, Vílchez-PérezM,Gargallo-Albiol J, Arnabat-Domínguez J, Gay-Escoda C. Efficacy of lowlevel laser therapy in the management of pain, facial swelling, and postoperative trismus after a lower third molar extraction. A preliminary study. Lasers Med Sci 2012; 27: 559- 66 .

13. Aras M, Güngormus M. The effect of low-level laser therapy on trismus and facial swelling following surgical extraction of a lower third molar. Photomed Laser Surg 2009; 27:21-04.

14. Aras MH, Gu M. Placebo-controlled randomized clinical trial of the effect two different low-level laser therapies (LLLT) - Intraoral and extraoral-On trismus and facial swelling following surgical extraction of the lower third molar. Lasers Med Sci 2010; 25: 641-45.

15. Eshghpour M, Ahrari F, Takallu M. Is Low-Level Laser Therapy Effective in the Management of Pain and Swelling After Mandibular Third Molar Surgery? Journal of Oral and Maxillofacial Surgery. 2016; 74: 1322-8.
16. Saber K, Chiniforush N, Shahabi S. The effect of low-level laser therapy on pain reduction after third molar surgery. Minerva Stomatol 2012; 61: 319-22.

17. Noroozi AR, Philbert RF. Modern concepts in understanding and management of the "dry socket" syndrome: comprehensive review of the literature. Oral Med Oral Pathol Oral Radiol Endod 2009; 107:305.

18. Markovic A, Todorovic L: Effectiveness of dexamethasone and low-power laser in minimizing oedema after third molar surgery: A clinical trial. Int J Oral Maxillofac Surg 2007; 36: 226.

19. Fernando S, Hill CM, Walker R. A randomised double blind comparative study of low-level laser therapy following surgical extraction of lower third molar teeth. Br J Oral Maxillofac Surg 1993; 31: 170-2.

20. Carrillo J S, Calatayud J, Manso, F J, Barberia E, MartinezJM and Donado M. A randomized double-blind clinical trial on the effectiveness of helium-neon laser in the prevention of pain, swelling and trismus after removal of impacted third molars. Int Dent J 1990: 40, 31-36. 